\begin{tabular}{c} 
International Journal of Engineering \& Technology, $7(4.30)(2018) 285-290$ \\
International Journal of Engineering \& Technology \\
WPC \\
Website: www.sciencepubco.com/index.php/IJET \\
Research paper \\
\hline
\end{tabular}

\title{
Dynamic Programming to Solve Picking Schedule at the Tea Plantation
}

\author{
Siti Mahsanah Budijati ${ }^{1 *}$, Bermawi Priyatna Iskandar ${ }^{2}$ \\ ${ }^{1}$ Industrial Engineering Department, Faculty of Industrial Technology, Universitas Ahmad Dahlan, Yogyakarta, Indonesia \\ ${ }^{2}$ Industrial Engineering, Faculty of Industrial Technology, Institut Teknologi Bandung, Indonesia \\ *Corresponding author E-mail: smbudijati@ie.uad.ac.id
}

\begin{abstract}
The tea picking schedule at PT Perkebunan Ciater is set to be the same for all plantation blocks. In fact, the altitude from sea level and the pruning age of each plantation block is different, this results in the difference of buds' growth. The implementation of the same picking schedule causes the quality and quantity of tea buds often could not be fulfilled. This research is to determine the precise picking schedule by considering the buds' growth of each plantation block. Two steps are implemented to solve the problem. The first step is to look for picking period and the pattern of buds' quality for each plantation block, which corresponds to the altitude of the location and the pruning age. The regression method is applied in this first step. The buds' quality pattern is then used to determine the cost of decreasing buds' quality and the costs of the buds that left in the plantation. The second step is to develop the picking schedule using dynamic programming, which minimizes the total cost of picking. In addition to this, we also develop a rolling schedule, which schedule time interval is three days. The model results show that the proposed schedule gives a better total cost than the current schedule and the buds' quality target is easier to achieve.
\end{abstract}

Keywords: Dynamic Programming; Minimizes Cost; Picking Schedule.

\section{Introduction}

Quality is one of the key competitions in marketing of a product. Tea is one of the products that relies on quality as the key competition in its marketing. Most of the products of tea plantation in Indonesia are intended for export and the marketing process is arranged by an auction system. In this auction system, the product quality is a crucial factor for product pricing.

A tea plantation applies quality and quantity standards in the harvesting of tea. In order to meet the expected standards, the company arranges the tea picking schedule. The arrangement of picking schedule is adjusted to the growth of tea bud. Meanwhile, the growth of tea bud, among others, is affected by the altitude from sea level and the pruning age.

The tea picking schedule at PT Perkebunan Ciater is set to be same for all plantation blocks, that is every 12-14 days. In fact, the altitude from sea level and the pruning age of each plantation block is different, this results in a difference of bud growth. The implementation of the same picking schedule causes the quality and quantity of tea buds often could not be fulfilled.

Therefore, it is necessary to determine the precise picking schedule by considering the bud growth of each plantation block. In addition, it is also necessary to arrange the picking reschedule for updating if the picking plan could not be implemented.

Dynamic programming is one of the methods that can be used to solve scheduling problem. Some research showed the implementation of dynamic programming in the scheduling problems, among others [1] proposed dynamic programming heuristic solution procedure to study the utilization of outsourcing as a way to overcome the supply chain disruptions in production scheduling in the presence of sudden consumer orders. Meanwhile [2] applied dy- namic programming to schedule surgery at the hospital in order to minimize the waiting time between patient requests and surgery schedules, overtime hours in the operating room and availability of bed in wards. [3] implemented pseudo-polynomial dynamic programming to minimize the number of tardy weighted jobs, determining the due dates, resources allocation as well as batch delivery costs. Moreover [4] used the dynamic programming to schedule aircraft landings on a single runway in both static and dynamic problem. [5] proposed an exact algorithm based on dynamic programming to find optimal sequences for the job-shop scheduling problem. [6] developed a stochastic dynamic programming model to optimize aircraft replacement scheduling by taking into consideration the fluctuations in the market demand and the status of the aircraft. Furthermore [7] developed approximate dynamic programming (ADP) algorithms to solve stochastic project scheduling problems. [8] developed adaptive dynamic programming algorithms to schedule consecutive appointments with the consideration of patient preferences in order to maximize the patient satisfaction level. [9] proposed a new dynamic programming algorithm for solving scheduling problem of independent tasks with common due date and to minimize the total weighted tardiness.

In addition, dynamic programming is also used for problem solving on technology replacement related to capacity planning as in [10]. Moreover [11] developed dynamic programming as a method of controlling demand through the pricing of delivery time at an e-grocer receiving orders via online booking system. Meanwhile [12] developed dynamic programming model for environmental decision-making process in coal mining investment. Related to layout optimization [13] proposed a new model based on dynamic programming to make a trade-off between reliability and cost for the layout design. As for [14] applied dynamic program- 
ming in assembly line balancing especially for solving resource constrain.

Some authors used dynamic programming to solve inventory problems, such as [15] used dynamic programming to complete a stochastic multi period inventory replenishment problem on supplier in a reverse supply chain. [16] used forward approximate dynamic programming to find out the solution of a multi locations stochastic inventory system. [17] developed model based on dynamic programming for a finite horizon single product inventory with uncertain probability distribution demand. Meanwhile [18] applied algorithm that reformulated the dynamic programming recursion as a mixed integer linear programming in the inventory scheduling problem.

In the knapsack problems, some authors considered the uses of dynamic programming too, that is [19] proposed a dynamic programming algorithm for the knapsack problem with setup that common in production planning applications, [20] developed two dynamic programming algorithms where the first algorithm was proposed for linear complexity on the number of items, while the latter was used for linear complexity at the knapsack capacity. Moreover [21] proposed a dynamic programming algorithm for knapsack packing with minimum cost and knapsack covering with maximum profit.

Other research area that uses dynamic programming was routing and transportation. [22] proposed a dynamic programming model to minimize transportation cost for multimodal transport operator. [23] combined a dynamic programming and ant colony optimization for emergency materials transportation model development in disasters situation. Moreover [24] offered an ADP approach to optimize time for handling and determine space to store in a coil warehouse. Meanwhile [25] proposed a markovian decision model and ADP to solve vehicle routing problem for emissions minimization, whereas [26] combined a genetic algorithm and exact dynamic programming procedure for green vehicle routing and scheduling problem.

Dynamic programming is used to manage at a plantation too. [27] showed the use of the model to optimize replanting policy that considerate $\mathrm{CO} 2$ emission and commercial benefits. In this paper dynamic programming was used to propose tea picking schedule which minimizes the total cost of picking.

\section{Model Development}

\subsection{Notation of the model}

The notations used in the model are:

Decision variable

$\mathrm{x}_{\mathrm{ni}}$ : the weight of tea buds picked in period $\mathrm{n}$, at the plantation block i, which the buds are picked according to the picking schedule.

$\mathrm{y}_{(\mathrm{n}-\mathrm{a}) \mathrm{i}}$ : the weight of tea buds picked in period $\mathrm{n}$, at the plantation block $i$, which the buds are the residual from picking period $\mathrm{n}$-a $\mathrm{a}=1$ or 2 (delays since period $\mathrm{n}$ )

Supply side

$\mathrm{S}_{\mathrm{ni}} \quad$ : tea buds availability in period $\mathrm{n}$, at the plantation block $\mathrm{i}$ (which is available on picking schedule)

$\mathrm{S}_{\mathrm{n}} \quad$ : the total of tea buds availability in period $\mathrm{n}$, at all plantation blocks

$$
S_{n}=\sum_{i=1}^{I} S_{n i}
$$

$l_{(\mathrm{n}-\mathrm{a}) \mathrm{i}} \quad:$ the residual tea buds from period $\mathrm{n}$-a, at the plantation block i

$\mathrm{L}_{(\mathrm{n}-\mathrm{a})}$ : the total of residual tea buds from period $\mathrm{n}-\mathrm{a}$, at all plantation blocks
$L_{n-a}=\sum_{i=1}^{I} l_{(n-a) i}$

$\mathrm{G}_{\mathrm{n}-1} \quad$ : the total of residual tea buds from all periods before period $n$

$G_{n-1}=L_{n-2}+L_{n-1}$

$l_{\mathrm{ni}} \quad:$ the residual tea buds in period $\mathrm{n}$, at the plantation block $\mathrm{i}$

$l_{n i}=s_{n i}-x_{n i}$

$\mathrm{L}_{\mathrm{n}} \quad$ : the total of residual tea buds in period $\mathrm{n}$, at all plantation blocks

$L_{n}=\sum_{i=1}^{I} l_{n i}$

$\mathrm{G}_{\mathrm{n}} \quad$ : the total of residual tea buds in the end of period $\mathrm{n}$

$G_{n}=L_{n-1}+L_{n}$

Demand side

$\mathrm{d}_{\mathrm{n}} \quad$ : the demand of period $\mathrm{n}$

Picking cost

$\mathrm{C}_{\mathrm{ni}}\left(\mathrm{x}_{\mathrm{ni}}\right) \quad$ : picking cost of $\mathrm{x}$ tea buds in period $\mathrm{n}$, at plantation block i

$\mathrm{B}_{(\mathrm{n}-\mathrm{a}) \mathrm{i}}(\mathrm{y}(\mathrm{n}-\mathrm{a}) \mathrm{i})$ : picking cost of residual y tea buds in period $\mathrm{n}$, at plantation block $i$, which the buds are the residual from picking period $n-a$

The picking cost is consist of:

Labor $\operatorname{cost}\left(\mathrm{C}_{\mathrm{L}}\right)$

$C_{L}=r_{i} \cdot z_{i}$

$\mathrm{r}_{\mathrm{i}} \quad$ : the labour wage of each $\mathrm{kg}$ of tea buds at plantation block i, based on the picking capacity and buds' analysis results

$\mathrm{Zi} \quad$ : the weight of tea buds picked at the plantation block $\mathrm{i}$

Transportation cost $\left(\mathrm{C}_{\mathrm{j}}\right)$

Transportation cost is determined by the distance from the plantation block $\mathrm{i}$ to the factory and the number of trucks. Truck capacity is $2000-2500 \mathrm{~kg}$ of tea buds. Each truck is only used for one plantation block.

The function of transportation cost is

$C_{j}=\left\{\begin{array}{cl}1359 \cdot H_{i} & \text { for } 0<z_{i} \leq 2500 \\ (2.1359) \cdot H_{i} & \text { for } 2500<z_{i} \leq 5000 \\ (3.1359) \cdot H_{i} & \text { for } 5000<z_{i} \leq 7500 \\ & \text { etc. }\end{array}\right.$

$\mathrm{H}_{\mathrm{i}} \quad$ : the distance from the plantation block $\mathrm{i}$ to the factory

Thus, the picking cost is the labour cost plus transportation cost, namely:

$C_{n i}\left(x_{n i}\right)=C_{L}+C_{J}$

$B_{(n-a) i}\left(y_{(n-a) i}\right)=C_{L}+C_{J}$

Losses cost

$\mathrm{T}_{\mathrm{ni}} \quad$ : losses cost due to the percentage of old buds picked more than $30 \%$ in period $n$, at the plantation block $i$, which the buds are picked according to the picking schedule.

$\mathrm{T}_{(\mathrm{n}-\mathrm{a}) \mathrm{i}} \quad$ : losses cost due to the percentage of old buds picked more than $30 \%$ in period $n$, at the plantation block $\mathrm{i}$, which the buds are the residual from picking period $n-a$

Assume: the number of broken buds is $5 \%$, if the old buds increased by $1 \%$ or the number of the old buds $31 \%$, 
then the percentage of good buds fell $1 \%$ or remaining to $64 \%$.

$\mathrm{O}_{\mathrm{n}} \quad$ : losses due to remaining buds at the plantation block in period $\mathrm{n}$ (because of incomplete picking at a plantation block in one day), where the losses depend on buds growth rate.

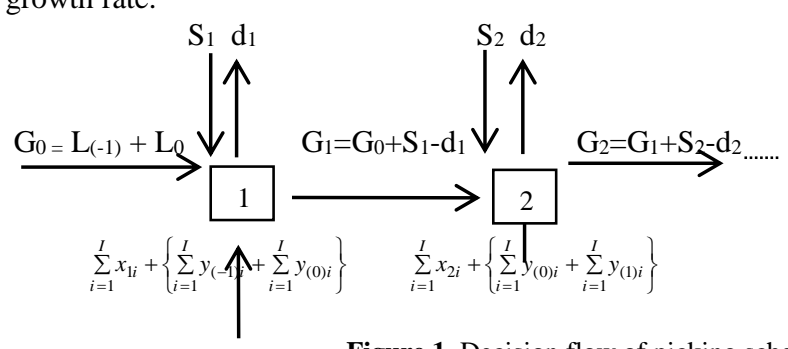

Index

$\mathrm{n} \quad$ : period $=1,2,3, \ldots, \mathrm{N}$

i : plantation block $=1,2,3, \ldots, \mathrm{I}$

Figure 1. Decision flow of picking scheduling model from stage 1 to $\mathrm{N}$

\subsection{Description of decision flow}

From Figure 1 it can be explained that in stage (period) 1 there is a supply of tea buds, namely $S_{1}$ (the total of tea availability in period 1, at all plantation blocks) that can be picked in period 1 according to the age of picking. Meanwhile, there are also supplies of tea buds from the remaining of 2 consecutive periods before period $1\left(\mathrm{G}_{0}=\mathrm{L}_{(-1)}+\mathrm{L}_{0}\right)$. Moreover, the demand of period 1 is $\mathrm{d}_{1}$. With the supplies $S_{1}$ and $G_{0}$ as well as the demand $d_{1}$, the decision variable for period 1 is $\sum_{i=1}^{I} x_{1 i}+\left\{\sum_{i=1}^{I} y_{(-1) i}+\sum_{i=1}^{I} y_{(0) i}\right\}$ which means that the demand is fulfilled from three sources: (i) the sum of tea buds picked from plantation blocks 1 to I with picking age according to the picking schedule $\left(\sum_{i=1}^{I} x_{1 \bar{i}}\right)$; (ii) tea buds picked from plantation blocks 1 to I, which are the residual of picking from one previous period $\left(\sum_{i=1}^{I} y_{(0) \bar{i}}\right)$; (iii) tea buds picked from plantation blocks 1 to I, which are the residual picking from two previous periods $\left(\sum_{i=1}^{I} y_{(-1) i}\right)$. So, at the end of period 1, the remaining tea buds in the plantation blocks are $\mathrm{G}_{1}$ which can be used as a supply for period 2. Furthermore, with the same procedure for the decision flow of the next stages.

\subsection{Model formulation}

This model is a modification of inventory-production dynamic model. Thus, the formulation of dynamic programming is:

The objective function: $f_{n}\left(G_{n}\right)$

The minimum cost of tea picking from period 1 to period $n$, if there are a number of tea buds remaining in the plantation block $\left(G_{n}\right)$ at the end of the picking period.

$G_{n}=G_{n-1}+S_{n}-d_{n}$

$G_{n-1}=G_{n}-S_{n}+d_{n}$

Recursive function:

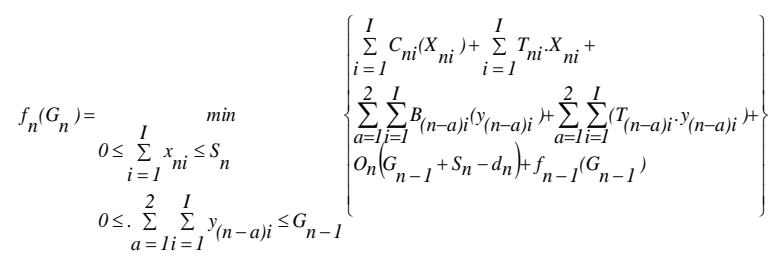

I: picked plantation blocks

$\mathrm{C}_{\mathrm{ni}}\left(\mathrm{X}_{\mathrm{ni}}\right)$ given by (9)

$\mathrm{B}_{(\mathrm{n}-\mathrm{a}) \mathrm{i}}(\mathrm{y}(\mathrm{n}-\mathrm{a}) \mathrm{i})$ given by $(10)$

$\mathrm{G}_{\mathrm{n}-1}$ given by (3) or (12)

The boundary conditions at $\mathrm{N}=1$

$$
f_{1}\left(G_{1}\right)=\underbrace{}_{\substack{i=\sum_{i=1}^{I} x_{1 i} \leq S_{1} \\
0 \leq \sum_{a=1}^{2} \sum_{i=1}^{I} y_{(1-a) i} \leq G_{0}}}\left\{\begin{array}{l}
\sum_{i=1}^{I} C_{1 i}\left(X_{1 i}\right)+\sum_{i=1}^{I} T_{1 i} \cdot X_{1 i}{ }^{+} \\
\sum_{a=1}^{2} \sum_{i=1}^{I} B_{(1-a) i}\left(y_{(1-a) i}\right)+\sum_{a=1}^{2} \sum_{i=1}^{I} T_{(1-a) i}\left(y_{(1-a) i}\right)+ \\
+O_{1}\left(G_{0}+S_{1}-d_{1}\right)
\end{array}\right\}
$$

\section{Model Analysis}

The picking schedule is arranged for every 3 periods (days), if the result of first day picking is known, then the picking schedule is updated for the next 3 days (the scheduling of period 2 to 4 ), and so on until the end of the picking period. The range of picking schedule within 3 days is based on the growth rate of tea buds.

The first step in this model analysis is to determine the pattern of buds' quality for each plantation block. The regression method is applied in this first step to obtain the equation of buds' decreasing quality that displayed in Table 1 .

\begin{tabular}{|c|c|c|}
\hline $\begin{array}{l}\text { The altitude } \\
\text { from sea level }\end{array}$ & Pruning age & $\begin{array}{c}\text { The equation of } \\
\text { buds' decreasing } \\
\text { quality }\end{array}$ \\
\hline \multirow{4}{*}{$\begin{array}{l}\text { plateau } \\
(>1200 \mathrm{~m})\end{array}$} & TP 1 (4 - 12 month) & $X=e^{3.336+0.00798 t}$ \\
\hline & TP 2 (13 - 24 month) & $X=26.88+0.305 t$ \\
\hline & TP 3 (25 - 36 month) & $\mathrm{X}=\mathrm{e}^{3.384+0.00537 \mathrm{t}}$ \\
\hline & TP 4 (37 - 48 month) & $X=28.596+0.193 t$ \\
\hline \multirow{4}{*}{$\begin{array}{l}\text { plains }(900- \\
1200 \mathrm{~m})\end{array}$} & TP 1 (4-12 month) & $\mathrm{X}=\mathrm{e}^{3.3394+0.0089 \mathrm{t}}$ \\
\hline & TP 2 (13 - 24 month) & $\mathrm{X}=27.3031+0.3053 \mathrm{t}$ \\
\hline & TP 3 (25 - 36 month) & $\mathrm{X}=\mathrm{e}^{3.38099+0.00511 \mathrm{t}}$ \\
\hline & TP 4 (37 - 48 month) & $\mathrm{X}=\mathrm{e}^{3.3867+0.00484 \mathrm{t}}$ \\
\hline \multirow{2}{*}{$\begin{array}{l}\text { lowland } \\
(600-900 \mathrm{~m})\end{array}$} & TP 1 (4 - 12 month) & $\mathrm{X}=\mathrm{e}^{3.165+0.0202 \mathrm{t}}$ \\
\hline & TP 2 (13 - 24 month) & $X=21.05+0.7125 t$ \\
\hline
\end{tabular}

Table 1: The equation of buds' decreasing quality

Note: $\mathrm{x}$ is the percentage of old buds $\mathrm{t}$ is period (day)

The percentage of old buds increases with increasing days, which means the quality of buds decreases.

To ilustrate model analysis as the second step of picking schedule model development, we used some data, namely: demand of buds, picking planning, the percentage of old buds for each plantation block, and the tea buds availability of each plantation block that are shown in Tables 2, 3, 4, and 5, respectively.

Table 2: Demand of the buds $(\mathrm{kg})$

Table 2: Demand of the buds (kg)
\begin{tabular}{|l|c|c|c|c|c|c|}
\hline Period $(\mathrm{n})$ & 1 & 2 & 3 & 4 & 5 & 6 \\
\hline $\begin{array}{l}\text { Demand } \\
\left(\mathrm{d}_{\mathrm{n}}\right)\end{array}$ & 8000 & 9000 & 8000 & 9000 & 9000 & 11000 \\
\hline
\end{tabular}


In addition, it is known that the picking capacity of each labour is tent of buds in good condition of $65 \%$ and $30 \%$ old buds). $40 \mathrm{~kg}$ and the picking wage of each $\mathrm{kg}$ is Rp160,00 (with the con-

Tabel 3: The picking planning

\begin{tabular}{|c|c|c|c|c|c|c|c|c|c|c|c|c|}
\hline \multirow{2}{*}{ No } & \multirow{2}{*}{$\begin{array}{c}\text { Name of } \\
\text { block }\end{array}$} & \multirow{2}{*}{$\begin{array}{l}\text { Distance from } \\
\text { factory }(\mathrm{km})\end{array}$} & \multirow{2}{*}{$\begin{array}{l}\text { The altitude } \\
\text { from sea level } \\
(\mathrm{m})\end{array}$} & \multirow{2}{*}{$\begin{array}{c}\text { Purning age } \\
\text { (month) }\end{array}$} & \multirow{2}{*}{$\begin{array}{l}\text { The day of } \\
\text { picking }\end{array}$} & \multicolumn{6}{|c|}{ date } & \multirow{2}{*}{$\begin{array}{c}\text { The remaining } \\
\text { buds }(\mathrm{kg})\end{array}$} \\
\hline & & & & & & 3 & 4 & 5 & 6 & 7 & 8 & \\
\hline 1 & Dawuan I & 5 & 1175 & 39 & 7 & 9 & 10 & 11 & 3000 & 1 & 2 & \\
\hline 2 & Dawuan II & 5 & 1105 & 44 & 10 & 11 & 12 & 13 & 14 & 2500 & 2500 & \\
\hline 3 & Cinampel & 7 & 1110 & 5 & 12 & 13 & 14 & 15 & 16 & 2000 & 3000 & \\
\hline 4 & Belendung II & 7 & 1190 & 25 & 13 & 3500 & 5000 & 4000 & 3 & 4 & 5 & \\
\hline 5 & Wates & 10 & 1500 & 35 & Picking day & 1000 & 2 & 3 & 4 & 5 & 6 & \\
\hline 6 & Panorama & 9 & 1285 & 53 & 12 & 13 & 14 & 15 & 16 & 1500 & 3500 & 3500 \\
\hline 7 & Talaga & 6 & 1335 & 47 & 13 & 14 & 15 & 2000 & 4000 & 1000 & 3 & \\
\hline 8 & Cicenang & 7 & 1360 & 45 & 17 & 3500 & 4000 & 2000 & 3 & 4 & 5 & \\
\hline 9 & Sela Batu & 5 & 1350 & 6 & 9 & 10 & 11 & 12 & 2000 & 2000 & 2000 & \\
\hline & Total (kg) & & & & & 8000 & 9000 & 8000 & 9000 & 9000 & 11000 & \\
\hline
\end{tabular}

Tabel 4. The percentage of old buds for each plantation block

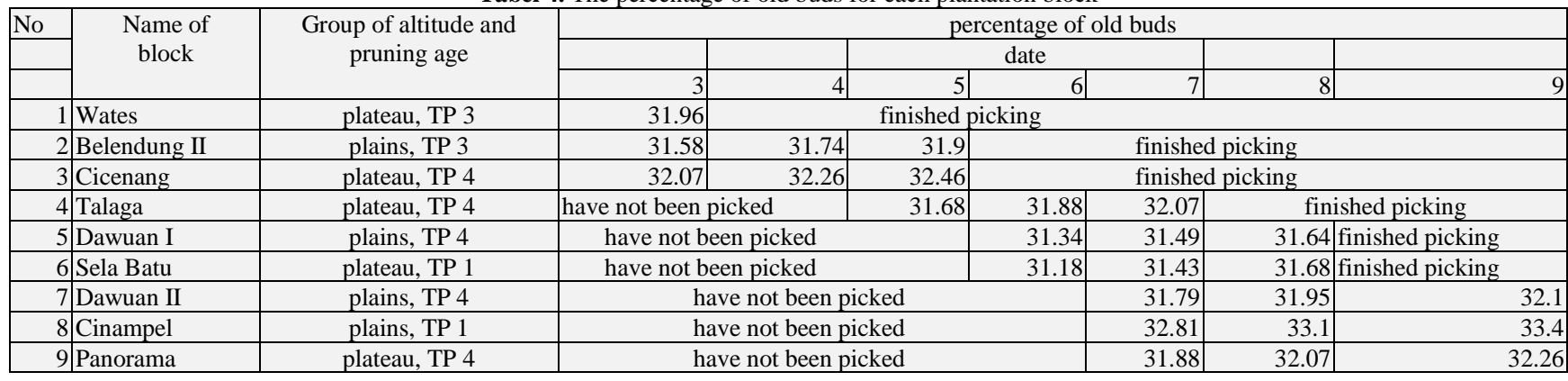

The provision of losses costs due to tea buds picked does not match the standard of quality, there is a policy of reducing wages per $\mathrm{kg}$, consisting of:

1. Reduction of $\mathrm{Rp} 3,00 / \mathrm{kg}$ for each $1 \%$ decreasing of buds quality from $70 \%$ to $62 \%$ or old buds of $25 \%$ to $33 \%$.

2. Reduction of $\mathrm{Rp} 6,00 / \mathrm{kg}$ for each $1 \%$ decreasing of buds quality from $<62 \%$ to $60 \%$ or old buds of $>33 \%$ to $35 \%$.

3. Reduction of $\mathrm{Rp} 9,00 / \mathrm{kg}$ for each $1 \%$ decreasing of buds' quality from $<60 \%$ to $56 \%$ or old buds of $>35 \%$ to $39 \%$.

Table 5: The tea buds availability of each plantation block

\begin{tabular}{|c|l|cc|}
\hline Period (n) & \multicolumn{1}{|c|}{ Name of block (i) } & $\begin{array}{c}\text { tea buds availability }\left(\mathrm{s}_{\mathrm{n} i}\right) \\
\text { in kg }\end{array}$ \\
\hline 0 & Wates (must be picked) & 1000 & $\left(\mathrm{G}_{0}\right)$ \\
\hline \multirow{2}{*}{1} & Belendung II & 12500 & $\left(\mathrm{~s}_{11}\right)$ \\
\cline { 2 - 4 } & Cicenang & 9500 & $\left(\mathrm{~s}_{12}\right)$ \\
\hline \multirow{3}{*}{3} & Talaga & 7000 & $\left(\mathrm{~s}_{31}\right)$ \\
\hline \multirow{3}{*}{5} & Dawuan I & 3000 & $\left(\mathrm{~s}_{41}\right)$ \\
\cline { 2 - 4 } & Sela Batu & 6000 & $\left(\mathrm{~s}_{42}\right)$ \\
\hline \multirow{3}{*}{5} & Dawuan II & 5000 & $\left(\mathrm{~s}_{51}\right)$ \\
\cline { 2 - 4 } & Cinampel & 5000 & $\left(\mathrm{~s}_{52}\right)$ \\
\cline { 2 - 4 } & Panorama & 8500 & $\left(\mathrm{~s}_{53}\right)$ \\
\hline
\end{tabular}

Furthermore, by applying equations (1) to (14), the solutions are obtained. For the boundary condition $\mathrm{N}=1$, the solution is displayed in Table 6. For $\mathrm{N}=2$, the solution is displayed in Table 7, and for $\mathrm{N}=3$, the solution is displayed in Table 8 .

To illustrate the results of the calculation, an example is given for the stage 1 of the first possible decision (first row, Table 6). For the stage 1 , there is a supply of $\mathrm{G}_{0}=1000$ (must be picked) plus supply of $s_{11}=12500$ and $s_{12}=9500$. Demand of the period 1 $\left(d_{1}\right)=8000$, then one of the possible decision is $y_{01}=1000$ (must be picked); $\mathrm{x}_{11}=0$ (there is no picking from $\mathrm{s}_{11}$ ); and $\mathrm{x}_{12}=7000$ (picking from $\mathrm{s}_{12}$ ), so the remaining tea buds in plantation blocks are $l_{11}=12500$ and $l_{12}=2500$.

The costs needed for the picking are:

\{Labor costs according to buds quality at each plantation block $\}+$ \{transportation costs from each plantation block to the factory, according to the distance of each plantation block $\}+\{$ cost of decreasing quality of the tea buds from each plantation block $\}+$ \{loss due to remaining buds in each plantation block\}

So the cost of picking for the first optimal decision in the stage 1 is:

$\{(160-(1.962 \times 3)) \times 1000\}+\{10 \times 1359 \times 1\}+\{1.962 \times 3 \times 1000\}$ $+\{(160-(2.07 \times 3)) \times 7000\}+\{7 \times 1359 \times 3\}+\{2.07 \times 3 \times 7000\}$ $+\{(31.742-31.58) \times 3 \times 12500\}+\{(32.263-32.07) \times 3 \times 2500\}$ $=1,329,651.5$

Then, by tracing the solution from Tables 6 to 8 in backward way, the result of picking schedule for the first 3 days, presented in Table 9 with the total cost is Rp. 4,130,207.50

To illustrate the cost comparison between the solution of the model and the original picking plan, it can be seen again the picking planning in Table 3. If the original plan is implemented, then the cost of picking that must be issued is:

(i) period 1 :

$\{((160-(1.962 \times 3)) \times 1000)+(10 \times 1359 \times 1)+(1.962 \times 3 \times$ $1000)\}+\{((160-(1.58 \times 3)) \times 3500)+(7 \times 1359 \times 2)+(1.58 \times$ $3 \times 3500)\}+\{((160-(2.07 \times 3)) \times 3500)+(7 \times 1359 \times 2)+$ $(2.07 \times 3 \times 4500\}+\{(31.742-31.58) \times 3 \times 9000\}+\{(32.263-$ $32.07) \times 3 \times 6000\}=1,339,490$

(ii) period 2 :

$1,339,490+\{((160-(1.742 \times 3)) \times 5000)+(7 \times 1359 \times 2)+$ $(1.742 \times 3 \times 5000)\}+\{((160-(2.263 \times 3)) \times 4000)+(7 \times 1359 \times$ $2)+(2.263 \times 3 \times 4000)\}+\{(31.9-31.742) \times 3 \times 4000\}+$ $\{(32.46-32.263) \times 3 \times 2000\}=2,820,620$

(iii) period 3 :

$2,820,620+\{((160-(1.9 \times 3)) \times 4000)+(7 \times 1359 \times 2)+(1.9 \times 3$ $\times 4000)\}+\{((160-(2.46 \times 3)) \times 2000)+(7 \times 1359 \times 1)+(2.46 \times$ $3 \times 2000)\}+\{((160-(1.69 \times 3)) \times 2000)+(6 \times 1359 \times 1)+(1.69$ $\times 3 \times 2000)\}+\{(31.88-31.69) \times 3 \times 5000\}=\mathbf{4 , 1 4 0 , 1 6 3}$

So, if the original plan is implemented, then the picking schedule for the first 3 days is as in Table 10 . 
Tabel 6: The solution of $\mathrm{f}_{1}$ for picking schedule of $\mathrm{N}=1$

\begin{tabular}{|c|c|c|c|c|c|c|c|c|c|c|c|c|c|}
\hline \multirow[t]{3}{*}{ stage } & \multicolumn{3}{|c|}{ Input variable } & \multirow{2}{*}{\multicolumn{3}{|c|}{ Possible decisions }} & \multirow{2}{*}{\multicolumn{3}{|c|}{ Optimal decision }} & \multirow{2}{*}{\multicolumn{2}{|c|}{$\begin{array}{c}\text { Output variable } \\
\mathrm{G}_{1}\end{array}$}} & \multirow{3}{*}{$\begin{array}{c}\text { Value of } \\
\text { possible } \\
\text { decisions (Rp) }\end{array}$} & \multirow{3}{*}{$\begin{array}{c}\text { Value of } \\
\text { optimal } \\
\text { decision (Rp) }\end{array}$} \\
\hline & \multirow{2}{*}{$\begin{array}{c}G_{0} \\
\begin{array}{l}l_{0 I} \text { (must be } \\
\text { picked) }\end{array}\end{array}$} & \multicolumn{2}{|c|}{$S_{I}$} & & & & & & & & & & \\
\hline & & $\mathrm{s}_{11}$ & $\mathrm{~s}_{12}$ & $\mathrm{y}_{01}$ & $\mathrm{x}_{11}$ & $\mathrm{x}_{12}$ & $\mathrm{y}_{01}$ & $\mathrm{x}_{11}$ & $\mathrm{x}_{12}$ & $l_{l 1}$ & $l_{12}$ & & \\
\hline \multirow[t]{5}{*}{1} & 1000 & 12500 & 9500 & 1000 & 0 & 7000 & 1000 & 0 & 7000 & 12500 & 2500 & $1,329,651.5$ & $1,329,651.5$ \\
\hline & 1000 & 12500 & 9500 & 1000 & 2500 & 4500 & 1000 & 2500 & 4500 & 10000 & 5000 & $1,329,884$ & $1,329,884$ \\
\hline & 1000 & 12500 & 9500 & 1000 & 5000 & 2000 & 1000 & 5000 & 2000 & 7500 & 7500 & $1,330,116.5$ & $1,330,116.5$ \\
\hline & 1000 & 12500 & 9500 & 1000 & 7000 & 0 & 1000 & 7000 & 0 & 5500 & 9500 & $1,330,302.5$ & $1,330,302.5$ \\
\hline & 1000 & 12500 & 9500 & 1000 & 2000 & 5000 & 1000 & 2000 & 5000 & 10500 & 4500 & $1,329,837.5$ & $1,329,837.5$ \\
\hline
\end{tabular}

Tabel 7: The solution of $\mathrm{f}_{2}$ for picking schedule of $\mathrm{N}=2$

\begin{tabular}{|c|c|c|c|c|c|c|c|c|c|c|}
\hline \multirow[t]{2}{*}{ stage } & \multicolumn{2}{|c|}{ Input variable $\mathrm{G}_{1}$} & \multicolumn{2}{|c|}{$\begin{array}{l}\text { Possible } \\
\text { decisions }\end{array}$} & \multicolumn{2}{|c|}{$\begin{array}{l}\text { Optimal } \\
\text { decision }\end{array}$} & \multicolumn{2}{|c|}{$\begin{array}{c}\text { Output variable } \\
\mathrm{G}_{2} \\
\end{array}$} & \multirow[t]{2}{*}{ Value of possible decisions (Rp) } & \multirow[t]{2}{*}{$\begin{array}{l}\text { Value of optimal } \\
\text { decisions (Rp) }\end{array}$} \\
\hline & $l_{11}$ & $l_{12}$ & $\mathrm{y}_{11}$ & $\mathrm{y}_{12}$ & $\mathrm{y}_{11}$ & $\mathrm{y}_{12}$ & $l_{11}$ & $l_{12}$ & & \\
\hline \multirow[t]{11}{*}{2} & 12500 & 2500 & 6500 & 2500 & \multirow[t]{5}{*}{6500} & \multirow[t]{5}{*}{2500} & \multirow[t]{5}{*}{6000} & \multirow[t]{5}{*}{0} & $1329651.5+1480968=2810619.5^{*}$ & \multirow[t]{5}{*}{$2,810,619.5$} \\
\hline & 10000 & 5000 & 4000 & 5000 & & & & & $1329884+1480968=2810852$ & \\
\hline & 7500 & 7500 & 1500 & 7500 & & & & & $1330116.5+1480968=2811084.5$ & \\
\hline & 8000 & 7000 & 2000 & 7000 & & & & & $1330070+1480968=2811038$ & \\
\hline & 10500 & 4500 & 4500 & 4500 & & & & & $1329837.5+1480968=2810805.5$ & \\
\hline & 5500 & 9500 & 0 & 9000 & & & \multirow[t]{3}{*}{5500} & \multirow[t]{3}{*}{500} & $1330302.5+1481014.5=2811317$ & \multirow[t]{3}{*}{$2,810,852$} \\
\hline & 8000 & 7000 & 2500 & 6500 & & & & & $1330070+1481014.5=2811084.5$ & \\
\hline & 10500 & 4500 & 5000 & 4000 & 5000 & 4000 & & & $1329837.5+1481014.5=2810852 *$ & \\
\hline & 12500 & 2500 & 7500 & 1500 & \multirow[t]{3}{*}{7500} & \multirow[t]{3}{*}{1500} & \multirow[t]{3}{*}{5000} & \multirow[t]{3}{*}{1000} & $1329651.5+1481061=2810712.5 *$ & \multirow[t]{3}{*}{$2,810,712.5$} \\
\hline & 10000 & 5000 & 5000 & 4000 & & & & & $1329884+1481061=2810945$ & \\
\hline & 7500 & 7500 & 2500 & 6500 & & & & & $1330116.5+1481061=2811177.5$ & \\
\hline \multirow[t]{11}{*}{2} & 5500 & 9500 & 1500 & 7500 & \multirow{6}{*}{$\frac{6500}{9000}$} & \multirow[b]{3}{*}{2500} & \multirow[t]{3}{*}{4000} & \multirow[t]{3}{*}{2000} & $1330302.5+1481154=2811456.5$ & \multirow[t]{3}{*}{$2,810,991.5$} \\
\hline & 8000 & 7000 & 4000 & 5000 & & & & & $1330070+1481154=2811224$ & \\
\hline & 10500 & 4500 & 6500 & 2500 & & & & & $1329837.5+1481154=2810991.5 *$ & \\
\hline & 12500 & 2500 & 9000 & 0 & & 0 & \multirow[t]{3}{*}{3500} & 2500 & $1329651.5+1481200.5=2810852 *$ & $2,810,852$ \\
\hline & 10000 & 5000 & 6500 & 2500 & & & & & $1329884+1481200.5=2811084.5$ & \\
\hline & 7500 & 7500 & 4000 & 5000 & & & & & $1330116.5+1481200.5=2811317$ & \\
\hline & 5500 & 9500 & 2500 & 6500 & & & 3000 & 3000 & $1330302.5+1481247=2811549.5$ & $2,811,084.5$ \\
\hline & 8000 & 7000 & 5000 & 4000 & & & & & $1330070+1481247=2811317$ & \\
\hline & 10500 & 4500 & 7500 & 1500 & 7500 & 1500 & & & $1329837.5+1481247=2811084.5 *$ & \\
\hline & 10000 & 5000 & 7500 & 1500 & 7500 & 1500 & 2500 & 3500 & $1329884+1481293.5=2811177.5 *$ & $2,811,177.5$ \\
\hline & 7500 & 7500 & 5000 & 4000 & & & & & $1330116.5+1481293.5=2811410$ & \\
\hline 2 & 5500 & 9500 & 4000 & 5000 & & & 1500 & 4500 & $1330302.5+1481386.5=2811689$ & $2,811,224$ \\
\hline & 8000 & 7000 & 6500 & 2500 & & & & & $1330070+1481386=2811456$ & \\
\hline & 10500 & 4500 & 9000 & 0 & 9000 & 0 & & & $1329837.5+1481386.5=2811224 *$ & \\
\hline & 10000 & 5000 & 9000 & 0 & 9000 & 0 & 1000 & 5000 & $1329884+1481433=2811317 *$ & $2,811,317$ \\
\hline & 7500 & 7500 & 6500 & 2500 & & & & & $1330116.5+1481433=2811549.5$ & \\
\hline & 5500 & 9500 & 5000 & 4000 & & & 500 & 5500 & $1330302.5+1481479.5=2811782$ & $2,811,549.5$ \\
\hline & 8000 & 7000 & 7500 & 1500 & 7500 & 1500 & & & $1330070+1481479.5=2811549.5 *$ & \\
\hline & 7500 & 7500 & 7500 & 1500 & 7500 & 1500 & 0 & 6000 & $1330116.5+1481526=2811642.5 *$ & $2,811,642.5$ \\
\hline
\end{tabular}

Tabel 8: The solution of $\mathrm{f}_{3}$ for picking schedule of $\mathrm{N}=3$

\begin{tabular}{|c|c|c|c|c|c|c|c|c|c|c|c|c|}
\hline \multirow[t]{3}{*}{ stage } & \multicolumn{3}{|c|}{ Input variable } & \multirow{2}{*}{\multicolumn{3}{|c|}{ Possible decision }} & \multirow{2}{*}{\multicolumn{3}{|c|}{ Optimal decision }} & \multirow{3}{*}{ 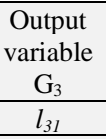 } & \multirow[t]{3}{*}{ Value of possible decisions (Rp) } & \multirow{3}{*}{$\begin{array}{l}\text { Value of } \\
\text { optimal } \\
\text { decisions } \\
(\mathrm{Rp})\end{array}$} \\
\hline & \multicolumn{2}{|c|}{$\begin{array}{c}\mathrm{G}_{2} \text { (must be } \\
\text { picked) }\end{array}$} & \multirow{2}{*}{$\begin{array}{l}\mathrm{S}_{31} \\
\mathrm{~s}_{31} \\
\end{array}$} & & & & & & & & & \\
\hline & $l_{11}$ & $l_{12}$ & & $\mathrm{y}_{11}$ & $\mathrm{y}_{12}$ & $\mathrm{X}_{31}$ & $\mathrm{y}_{11}$ & $\mathrm{y}_{12}$ & $\mathrm{X}_{31}$ & & & \\
\hline \multirow[t]{8}{*}{3} & 6000 & 0 & 7000 & 6000 & 0 & 2000 & \multirow[t]{8}{*}{6000} & \multirow[t]{8}{*}{0} & \multirow[t]{8}{*}{2000} & \multirow[t]{8}{*}{5000} & $2810619.5+1319588=4130207.5 *$ & \multirow[t]{8}{*}{$4,130,207.5$} \\
\hline & 5000 & 1000 & 7000 & 5000 & 1000 & 2000 & & & & & $2810712.5+1319588=4130300.5$ & \\
\hline & 4000 & 2000 & 7000 & 4000 & 2000 & 2000 & & & & & $2810991.5+1319588=4130579.5$ & \\
\hline & 3500 & 2500 & 7000 & 3500 & 2500 & 2000 & & & & & $2810852+1319588=4130440$ & \\
\hline & 2500 & 3500 & 7000 & 2500 & 3500 & 2000 & & & & & $2811177.5+1319588=4130765.5$ & \\
\hline & 1500 & 4500 & 7000 & 1500 & 4500 & 2000 & & & & & $2811224+1319588=4130812$ & \\
\hline & 1000 & 5000 & 7000 & 1000 & 5000 & 2000 & & & & & $2811317+1319588=4130905$ & \\
\hline & 0 & 6000 & 7000 & 0 & 6000 & 2000 & & & & & $2811642.5+1319588=4131230.5$ & \\
\hline
\end{tabular}

Tabel 9: The result of picking schedule model for the first 3 days

\begin{tabular}{|l|c|c|c|}
\hline \multirow{2}{*}{ Name of block } & \multicolumn{3}{|c|}{ date } \\
\cline { 2 - 4 } & 3 & 4 & 5 \\
\hline Wates & 1000 & & 6000 \\
\hline Belendung II & 0 & 6500 & 2000 \\
\hline Cicenang & 7000 & 2500 & 8000 \\
\hline Talaga & & & 9000 \\
\hline demand & 8000 & \multicolumn{2}{|c|}{} \\
\hline
\end{tabular}

Tabel 10: The result of original picking schedule for the first 3 days

\begin{tabular}{|l|c|c|c|}
\hline \multirow{2}{*}{ Name of block } & \multicolumn{3}{|c|}{ date } \\
\cline { 2 - 4 } & 3 & 4 & 5 \\
\hline Wates & 1000 & & 4000 \\
\hline Belendung II & 3500 & 5000 & 2000 \\
\hline Cicenang & 3500 & 4000 & 2000 \\
\hline Talaga & & & 8000 \\
\hline demand & 8000 & 9000 & \\
\hline
\end{tabular}


Thus the application of the picking schedule with dynamic programming approach provides a smaller cost (Rp.4,130,207.50) than the original picking schedule (Rp.4,140,163.00). Furthermore, for the next scheduling, after the picking results on the $3^{\text {rd }}$ date is known, then the schedule is made for the date of $4^{\text {th }}$ to $6^{\text {th }}$. And so on until the end of scheduling period.

\section{Conclusion}

The conclusion on this paper are made as follows:

i. The proposed model of picking schedule gives a better total cost. Although the difference in the value of the rupiahs between the model application and the original picking plan for the first 3 days is relatively small, but if the model is applied for long-term picking scheduling it will result in cost saving.

ii. The application of the model facilitates the achievement of the target quality of the tea buds picked, so that the decreasing quality of tea buds can be minimized. Furthermore, it will affects the quality of the tea products produced, which in turn affects the price and the level of tea sales on the market.

\section{References}

[1] Liu F, Wang J, Chen H \& Yang D (2014), Machine scheduling with outsourcing: coping with supply chain uncertainty with a second supplying source. The International Journal of Logistics Management 25(1), 133-159.

[2] Astaraky D \& Patrick J (2015), A simulation based approximate dynamic programming approach to multi-class, multi-resource surgical scheduling. European Journal of Operational Research 245(1), 309-319.

[3] Rasti-Barzoki M \& Hejazi SR (2015), Pseudo-polynomial dynamic programming for an integrated due date assignment, resource allocation, production, and distribution scheduling model in supply chain scheduling. Applied Mathematical Modelling 39, 3280-3289.

[4] Bennell JA, Mesgarpour M \& Potts CN (2017), Dynamic scheduling of aircraft landings. European Journal of Operational Research 258(1), 315-327.

[5] Gromicho JAS, van Hoorn JJ, Saldanha-da-Gama F \&Timmer GT (2012), Solving the job-shop scheduling problem optimally by dynamic programming. Computers \& Operations Research 39, 2968 2977.

[6] Hsu CI, Li HC, Liu SM \& Chao CC (2011), Aircraft replacement scheduling: A dynamic programming approach. Transportation Research Part E 47, 41-60.

[7] Li H \& Womer NK (2015), Solving stochastic resource-constrained project scheduling problems by closed-loop approximate dynamic programming. European Journal of Operational Research 246(1), 20-33.

[8] Wang J \& Fung RY (2015), Adaptive dynamic programming algorithms for sequential appointment scheduling with patient preferences. Artificial intelligence in medicine 63(1), 33-40.

[9] Tuong NH, Soukhal A \& Billaut JC (2010), A new dynamic programming formulation for scheduling independent tasks with common due date on parallel machines. European Journal of Operational Research 202(3), 646-653.

[10] Wang KJ \& Nguyen PH (2017), Capacity planning with technology replacement by stochastic dynamic programming. European Jour nal of Operational Research 260, 739-750.

[11] Yang X \& Strauss AK (2017), An approximate dynamic programming approach to attended home delivery management. European Journal of Operational Research 263(3), 935-945.

[12] Yu S, Gao S \& Sun H (2016), A dynamic programming model for environmental investment decision-making in coal mining. Applied Energy 166, 273-281.

[13] Tripathy PK, Dash RK \&Tripathy CR (2015), A dynamic programming approach for layout optimization of interconnection networks. Engineering Science and Technology, an International Journal 18(3), 374-384.

[14] Quyen NTP, Kuo RJ, Chen JC \& Yang CL (2017), Dynamic programming to solve resource constrained assembly line balancing problem in footwear manufacturing. Proceedings of the 4th Interna- tional Conference on Industrial Engineering and Applications (ICIEA), IEEE 66, 66-70.

[15] Lekkakos SD \& Serrano A (2016), Supply chain finance for small and medium sized enterprises: the case of reverse factoring. International Journal of Physical Distribution \& Logistics Management 46(4), 367-392.

[16] Meissner J \& Senicheva OV (2018), Approximate Dynamic Programming for lateral transshipment problems in multi-location inventory systems. European Journal of Operational Research 265(1), 49-64.

[17] Qiu R, Sun M \& Lim YF (2017), Optimizing (s, S) policies for multi-period inventory models with demand distribution uncertainty: Robust dynamic programing approaches. European Journal of Operational Research 261(3), 880-892.

[18] Rivotti P \& Pistikopoulos EN (2014), Constrained dynamic programming of mixed-integer linear problems by multi-parametric programming. Computers \& Chemical Engineering 70, 172-179.

[19] Chebil K \& Khemakhem M (2015), A dynamic programming algorithm for the knapsack problem with setup. Computers \& Operations Research 64, 40-50.

[20] Claßen G, Koster AM \& Schmeink A (2015), The multi-band robust knapsack problem-A dynamic programming approach. Discrete Optimization 18, 123-149.

[21] Furini F, Ljubić I \& Sinnl M (2017), An effective dynamic programming algorithm for the minimum-cost maximal knapsack packing problem. European Journal of Operational Research 262(2), 438-448.

[22] Hao C \& Yue Y (2016), Optimization on Combination of Transport Routes and Modes on Dynamic Programming for a Container Multimodal Transport System. Procedia Engineering 137, 382-390.

[23] Liu J \& Xie K (2017), Emergency materials transportation model in disasters based on dynamic programming and ant colony optimization. Kybernetes 46(4), 656-671.

[24] Yuan Y \&Tang L (2017), Novel time-space network flow formulation and approximate dynamic programming approach for the crane scheduling in a coil warehouse. European Journal of Operational Research 262(2), 424-437.

[25] Cimen M \& Soysal M (2017), Time-dependent green vehicle routing problem with stochastic vehicle speeds: An approximate dynamic programming algorithm. Transportation Research Part D: Transport and Environment 54, 82-98.

[26] Xiao Y \& Konak A (2017), A genetic algorithm with exact dynamic programming for the green vehicle routing $\&$ scheduling problem. Journal of Cleaner Production 167, 1450-1463.

[27] Diban P, Aziz MKA, Foo DCY, Jia X, Li Z \& Tan RR (2016), Optimal biomass plantation replanting policy using dynamic programming. Journal of Cleaner Production 126, 409-418. 